\title{
DÜBLIN
}

Technological University Dublin ARROW@TU Dublin

2015

\section{Designing the Identities of Engineers}

\author{
Mike Murphy \\ Technological University Dublin, mike.murphy@tudublin.ie \\ Shannon Chance \\ Technological University Dublin, shannon.chance@tudublin.ie \\ Eddie Conlon \\ Technological University Dublin, edward.conlon@tudublin.ie
}

Follow this and additional works at: https://arrow.tudublin.ie/engineducbks

Part of the Other Engineering Commons

\section{Recommended Citation}

Murphy, M., Chance, S. \& Conlon, E. (2015). Designing the Identities of Engineers. In Engineering Education and Practice in Context, Vol.2. Springer

This Book Chapter is brought to you for free and open access by the Engineering: Education and Innovation at ARROW@TU Dublin. It has been accepted for inclusion in Books/Book chapters by an authorized administrator of ARROW@TU Dublin. For more information, please contact arrow.admin@tudublin.ie, aisling.coyne@tudublin.ie, gerard.connolly@tudublin.ie.

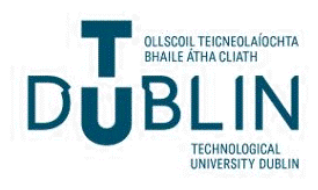




\title{
Chapter 3
}

\section{Designing the Identities of Engineers}

\author{
Mike Murphy, Shannon Chance \& Eddie Conlon
}

\begin{abstract}
In 2007 Gary Downey, Juan Lucena and Carl Mitcham argued that a "key issue in ethics education for engineers concerns the relationship between the identity of the engineer and the responsibilities of engineering work". They suggested that "one methodological strategy for sorting out similarities and differences in engineers' identities is to ask the 'who' question. Who is an engineer? Or, what makes one an engineer?" (Downey, Lucena \& Mitcham, 2007). This chapter explores these questions of who is an engineer and what makes one an engineer by examining how engineering and engineering technology students in Dublin Institute of Technology (DIT) describe and differentiate themselves. DIT offers both 4-year engineering degrees (that are equivalent to the educational standard required for professional status) and 3-year degrees in engineering technology. Annually DIT graduates the largest combined number of engineering and engineering technology majors in the country. We present results that show that there is no distinct sense of identity for a technologist. For faculty as well as engineering students and engineering technology students, design is perceived as a key differentiating activity that separates the engineer from the engineering technologist. Paradoxically, while all students chose DIT based on its reputation and practical focus, it is engineering technology students who indicated they are prepared for the 'real world' as they near graduation. Results also show, in terms of their own responses, that engineering and engineering technology students have fairly consistent views of their education and preparation for the workforce.
\end{abstract}

Keywords: self-direction, purpose, engineering identity, engineering technology, design, real world, career

\section{Introduction}

In the foreword to a book by Sheri Sheppard et al on educating engineers, Lee Shulman related an anecdote in which a number of senior (i.e., final year) engineering students from a highly regarded public university were asked to characterize the engineer's place relative to other professions by answering the question "What's an engineer?" Shulman explained:

Their response - collaboratively crafted and framed - was unforgettable: "An engineer is someone who uses math and the sciences to mess with the world - by designing and making things that people will buy and use; and once you mess with the world, you are responsible for the mess you've made" (quoted in Sheppard, Macatangay, Colby, \& Sullivan, 2009, p. ix). 
Engineering education has evolved differently in various countries. In the United States, engineering education has developed two broad streams: engineering and engineering technology. There, differentiation between the two streams is generally described by way of a theoretical-versus-applied approach, with different accreditation criteria for each. Graduates are differentiated by the name of the degree they earn (bachelor of engineering as opposed to bachelor of technology). In Germany, engineers are educated in technical universities and in universities of applied sciences (fachhochschulen). Their differentiation is similar to that in the USA, being along a theoretical-applied continuum, but graduates of both the universities and the universities of applied sciences earn engineering degrees.

Ireland provides an interesting example of these two typical ways of differentiating "engineering technology" from "engineering". This country has distinguished the two based on the relative levels of theory and application they offer. The separation along the theoretical-to-applied engineering continuum aligns structurally with the university-institute of technology dimension, with universities providing more theoretical "engineering" degrees and institutes of technology generally offering more applied "engineering technology" programs. But within Dublin Institute of Technology, programs at both levels are offered. Further, there is a well-established transfer route from engineering technology programs onto engineering programs.

DIT differentiates between traditional 4-year degrees in engineering (that are accredited as professional engineering programs) and 3-year degrees in engineering technology. This differentiation is made at enrolment, where engineering students are required to have earned higher college entrance exam scores than engineering technology students (based on Ireland's Leaving Certificate examination). The single largest differentiating factor between the incoming classes of engineering students (4-year cycle) and engineering technology students (3-year cycle) is in their mathematics ability at entry. To enroll in a 4-year engineering program directly from second-level school requires each student to achieve a minimum C3 grade in higher-level mathematics. To enroll in a 3-year engineering technology program requires a passing grade of D3 in lower-level mathematics. Survey responses consistently show that a significant percentage of students enroll in engineering technology at DIT because they want to become engineers but have not achieved the minimum mathematics standard in their Leaving Certificate examination. Upon completion of their 3-year program, students can apply to transfer onto the junior year (3rd year) of the 4-year engineering program, which they are allowed to do provided they achieve a minimum threshold grade. Consequently, approximately $50 \%$ of graduates from engineering technology programs transfer onto engineering programs.

What we set out to examine were the similarities and differences between how the two groups of students - engineering and engineering technology - describe themselves. Do the engineering technology students see themselves as engineers, technicians, or technologists? Are there common factors in the identity of engineering students across disciplines, or are identity factors discipline-specific? In this chapter, we examine the identities of students who are about to graduate in order to understand: (1) why the students chose to study engineering in the first place, (2) how their engineering teachers see, describe, and characterize the identity of their students and future graduates; and (3) how these students see and describe themselves as engineers, or technologists. We used Ireland's accreditation standards for each of the two different degree programs as a guide to writing a number of the survey questions, because we 
wanted to gauge if the differences (implied in the standards) were detected by the students themselves.

\section{What is Identity?}

Self-identity can be seen as the conception individuals develop of who and what they are (Tony Watson, 1997). Identity develops in the course of interactions with others. In a sense, an individual's life can be seen as a career during which the person moves through different situations, interacts with others, and adjusts to achieve a sense of selfhood. Watson (1997) asserts, "self-identity is constantly in the process of being won from the social environments in which we find ourselves" (p. 129).

There are two broad dimensions to identity formation: the invented and the constructed. Identity is a social product. It is continually appropriated by individuals for themselves as well as bestowed on individuals by others (Kerry Meyers et al., 2010; Paul Thompson \& David McHugh, 2002). People actively construct their identities out of the materials presented during social activities and in their various roles. Individuals engage in securing identities that can provide personal stability and help in directing their activity. Identity is thus a tool people use; it helps them project images appropriate to the specific social, cultural, and work contexts they encounter. There are, however, limits to this active creation of identities. The typified self tends to be created from factors that arise in various social situations that fall into specific categories.

Watson (1997) has identified two aspects of individual identity. The first is selfconcept involving such matters as self-efficacy, self-esteem, and self-confidence. According to Robin Leidner (2006), this can be derived from the experience of education or work providing the "satisfactions of feeling oneself competent to accomplish one's intentions, overcome difficulties (and) create something" (p. 436). The second is a social identity that includes various attitudes, values, beliefs, and commitments in relation to society and social institutions. Personal values are influenced by the culture of society and the groups within it; our social and professional identities are often shaped by occupational culture.

Personal and social identities are inevitably intertwined. For example, Leidner (2006) asserts participation in an occupational culture "frequently involves an explicit reframing of self-identity as well as development of a new collective identity" ( $p$. 436). She makes the point that in well-defined occupations, processes of initiation are explicitly intended to transform the identity of newcomers:

Novices gain skills and a body of practical and... abstract knowledge. When socialization is successful they also learn and internalize the occupation's ideology, ethos, traditions, and norms, including criteria for judgment, craft pride, and rules for interacting among themselves and various others. (p. 436)

The literature identifies two broad approaches to identity formation (see Jan Stets \& Peter Burke, 2000): (1) identity theory which focuses on roles and the manner in which individuals (through a process of identification) come to occupy a role and incorporate the meanings and expectations associated with that role into their sense of 'self', and (2) social identity theory where the emphasis is on group membership and self-categorization by individuals to identify themselves as members of particular groups. In this, "Having a particular social identity means being at one with a certain group, being like others in the group, and seeing things from the group's perspective" (p. 226). 
They argue for a more integrated view of the self and assert the differences between these theories are more of emphasis than of kind:

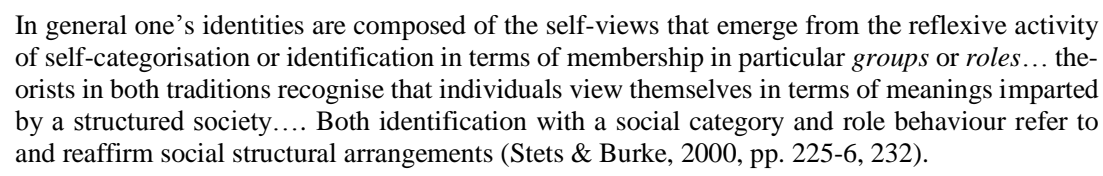

This is not simply an issue of personality; organizational, institutional, and situational factors play a role in shaping identity (Olga Pierrakos et al., 2010).

We can conclude that 'being' and 'doing' are both central features of one's identity. Moreover, central questions to ask in exploring engineering identities are: who is an engineer, what does an engineer do, what does performing the role of an engineer entail, and what are the responsibilities of engineers? Drawing on Michael Hogg and Deborah Terry (2000), Kevin Anderson et al (2010) argue that engineering groups imagine archetypes that capture dependent features of group membership which are abstractions of group features: "These archetypes then show what the group values and serve to distinguish the ways of doing and thinking of one group from another" (p. 157).

The approach described above requires us to focus not just on the emerging identities of engineering graduates but also on the way that the role of the engineer is socially constructed within different societies and how that role is reproduced (or challenged) for each new generation of engineers. A key focus must be on engineering education becasue "formative processes in education serve as key locations for negotiating and renegotiating of the relationship between the person of the engineer and the definition and responsibilities of engineering work" (Downey, Lucena \& Mitcham, 2007, p. 466). In the course of obtaining education, students will develop technical and professional expertise but will also "undergo changes in their identity and self-conception of what it means to be an engineer" (Pierrakos et al, 2010). Thus, Downey et al (2007) say, engineering educators typically bear primary responsibility for addressing and answering the question: What does it take to become a good engineer?

Of course there may be more than one answer to this question arising from national differences in the organization of engineering work and different approaches to the education of engineers. The two issues are clearly linked. Engineering, and technical work, is structured differently in different societies and the processes that reproduce the engineering and technical workforce also differ. The manner in which engineers are formed has implications for their understandings of their roles and their relationships with other groups - especially management (see Peter Meiksins \& Chris Smith 1996; Chris Smith 1987). It may be the case that the professional identity of engineers is weak, as other forms of self-categorization and identification have greater significance. This is a collective issue and not just an issue for individual engineers. Such is the case in Japan, where engineers have traditionally identified with the enterprise where they are employed rather than their profession (Downey, Lucena \& Mitcham, 2007, Meiksins \& Smith, 1987). National variations in the processes for reproducing engineering work and engineers led Meiksins and Smith (1963) to conclude it may be "impossible to develop a definition of what an engineer is, or where the boundaries of engineering lie, which would apply to all industrial capitalist societies" (p. 3). 
Andrew Jamison (2013) has mapped the relationship between different approaches to engineering education and different archetypes of engineering identity. He identified three broad approaches to engineering education: science-driven, market-driven and socially driven. These are related to three aspects of identity: academic, commercial and hybrid. However, in most societies these ideal types do not exist in a pure form.

Indeed the identification of deficiencies associated with the science-driven model has led to the development of a second layer of market-driven engineering education in many countries. It is aimed at the production of "more practically trained engineers" (Meiksins \& Smith, 1996, p. 245). The development of institutes of technology in Ireland can be seen to fit into this pattern. The Mulcahy Report (1967) set out the rationale for their formation in the following terms:

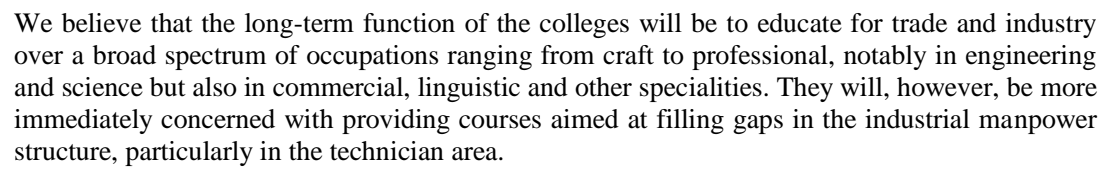

This fits in with a pattern - that can be identified in a number of countries - whereby the state defines various categories of technical worker based on the abstract-practical continuum. This increases the degree of hierarchy in technical labor, so that the workforce becomes "stratified by credentials and mode of entry into the technical workforce" and a direct correspondence emerges between the "the type of qualification possessed and the engineer's position in the division of labour" (Meiksins \& Smith, 1996, p. 240). This leads to a more fragmented occupational community for engineering.

Cutting across issues related to the structure of the engineering workforce are debates about what characterizes a good engineer. What makes a good engineer is contested (see Matthew Wisnioski, 2012). Debates in engineering education have focused on shortcomings of traditional engineers and argued for the need for "New Engineers" (Sharon Beder, 1988) and, more recently, for "Green Engineers" (Jamison, 2013).

Jamison (2013) voices the need for educators and professionals to conceptualize engineering as both a social and technical activity. This includes the need: (1) for the technical component of engineering to be combined with social and cultural understandings, and (2) the need for engineers to have skills and capacities other than technical proficiency. All this should be done with the aim of furthering public, rather than corporate, good. Competencies for sustainable engineering span a number of knowledge domains; they include skills such as critical and systematic thinking, the capacity to work with and integrate the perspectives of others, sustainable development values and ethics, and a wide range of interpersonal skills (Iacovos Nicolaou \& Eddie Conlon, 2013).

Kevin Anderson et al (2010) interviewed engineers in six firms and noted the significance of communication skills. As one engineer told them: "Engineering is the easy part. It's the people who are difficult" (p. 162). These researchers found that engineers "walked around with an unstated equation in their head: Problem solver + team player + life-long learner" (p. 166). Despite this finding, they discovered engineers still value the technical core of engineering work: "Authentic engineering tends 
to be viewed as getting one's hands dirty" (169) 1 and they struggled with including non-technical elements in their definition of engineering. Yet they still believed that effective communication is intimately intertwined with engineering problem solving and that engineering cannot be done without it. They also did not see themselves as being engineers in order to contribute to the public good. "Their identity was more likely to be grounded in solving problems well - for themselves, for their team, for their organization and for their client" (p. 170). This can be explained to an extent by their understanding of the constraints, particularly fiscal constraints, they faced as engineers and the realization that the demands of engineering work do not always, as one engineer put it, "mesh with the romantic visions he held as an undergraduate" (p. 166).

The undergraduates studied by Meyers et al (2010) identified three factors which define engineering: (1) ability to make competent design decisions, (2) capability to work with others, and (3) maturity to accept responsibility for one's actions (p. 1554).

What emerges from this is that the identity of engineers can be explored through looking at: (1) how they understand their engineering work, (2) the skills and relationships they need to do that work, and (3) how they understand their responsibilities as engineers. But such an understanding must be contextualized with regard to the organization of engineering (work and education) and the archetypes of engineers that are promoted within these structures.

We know that educational institutions shape student identities both during the recruitment process and while they are studying to be engineers. For instance, Carney Strange and James Banning (2001) argue that certain types of colleges attract specific types of students. The scholars identify four general typologies of (American) colleges and four typologies of (American) college students. They describe relationships between the two sets of typologies. Where the type of institution successfully matches the 'type' of student who attends (e.g., the student's interests, expectations, temperament, inclinations, and abilities) an appropriate 'fit' is usually achieved. In the process of finding the right fit, students typically absorb messages that colleges send out (using websites, brochures, campus tours, and the like). Students do this prior to selecting the specific college where they will enroll. This helps match their own values and personal identities to the college. Once a student arrives on campus, he or she typically accepts the values of that community and begins to internalize such messages even more deeply. However, where there is misalignment between the student's personal values and those of the campus community, the student may become unhappy and leave. Thus, the identity of the college (and its programs) is shaped by, and helps shape, the identities of the individuals who join and maintain it.

Reed Stevens et al (2008) and Kerry Meyers et al (2010) have pointed to the importance of the labeling and categorization processes that take place in education. How institutions identify students as engineers has a profound effect on students' identification of themselves as engineers (Stevens et al). It matters "what we call students and more specifically the curricular and institutional structures that classify students within departments... as this contributes to the social portion of psychosocial identity" (Meyers et al, pp. 1555, 1558).

\footnotetext{
${ }^{1}$ Compare this with research by Llewellyn Mann et al (2009) on engineering graduates: "Most of the participants talked about being able to fall back on their technical knowledge when they were unsure of how to proceed. Their technical knowledge became almost a safety blanket, something that makes them sure they are an engineer" (emphasis added).
} 
A further issue is that there seems to be diversity in how engineering educators understand engineering. Alice Pawley (2009) studied how engineering faculty define engineering. While common themes emerged - such as problem solving, applied science, and making things - there were a range of beliefs as to what engineering is. According to Meyers et al (2010) "Many engineering educators are challenged to define succinctly what engineering is to students" (p. 1557).

\section{Study Methodology}

Our work in this chapter is based on a mixed-methods exploratory study that sought to address the following questions:

1. How do students nearing graduation in engineering and engineering technology identify themselves?

2. To what extent are their identities similar?

3. What differences exist between the groups in what they think they have learned and what they envision as their future roles?

Our study is situated within the constructivist paradigm. In conducting it, we have sought, by exploring points of similarity and contrast, to understand how groups of students see themselves. We began by developing research questions that aligned with constructivist beliefs that groups of people define themselves - and thus shape their own culture - collectively. Together, they develop a shared sense of reality that constitutes truth for them. In this study, we sought to identify points of shared understanding among the two groups (engineering and engineering technology students) as well as factors that distinguished the two groups from each other in the context of a DIT education. We included final year engineering and engineering technology students at DIT in the general fields of mechanical and electrical engineering.

To gain a basic understanding of relevant issues and begin to identify important factors differentiating the student groups, we conducted interviews with faculty from two countries (Ireland and the USA). We analyzed their responses qualitatively and used our findings to construct an instrument for surveying students. We pilot tested the surveys using think-aloud protocols; then we disseminated the survey to graduating students via email. Responses were analyzed using IBM's Statistical Package for Social Sciences (SPSS, version 20) to detect statistically significant differences in the ways the two groups responded. To broaden our understanding of student perception, we examined a series of surveys conducted with students entering DIT in the years 2003 to 2007 . We also drew from preliminary results in conducting a brief case study of how both student groups tackled a design challenge.

Thus, the study reported in this chapter utilized a four-strand approach. Strand 1 involved conducting and analyzing semi-structured interviews with seven senior lecturers who teach final year engineering or engineering technology students. Strand 2 involved an online survey of final year students from engineering and engineering technology programs. Strand 3 involved a review of previous surveys of incoming freshman (i.e. first year) students that included a range of questions such as why they chose to study engineering and who influenced their decisions. Strand 4 is a case study of design approaches that differentiate the two groups of students. This case study is included because the two groups of students reported significantly different perceptions of the role of design in their work.

\section{Strand 1: Faculty Perspectives}


Consistent with the constructivist paradigm, we believe that educators are involved in the dialogue of professional identity and are not separate from it. We also wanted to address existing confusion on the topic of engineering versus engineering technology that seems evident in DIT and other institutions. We interviewed five DIT faculty members. Our objectives were: (1) to elicit how these educators describe and characterize the identity of their final year students and soon-to-be-graduates, and (2) to understand the language used by educators in describing their students. We analyzed these interviews in search of themes that could inform our interviews with students. We also interviewed two faculty members from Purdue University as external reference, and because we hope to expand this study in the future to the discussion in the United States on engineering and technology.

\section{Findings from Faculty Interviews}

Two main themes became evident in DIT faculty responses related to the question: What is it that engineering technologists (or engineers) do? The first theme is that faculty members see engineers and engineering technologists as generally performing different roles. The second is that the two groups also perform these roles at different depths or levels. Sample comments, illustrating this, are shown in Table 1.

\section{Table 1. Respective Roles}

\begin{tabular}{|l|c|}
\hline Role of Engineering Technologists & Role of Engineers \\
\hline ○"Engineering technologists clarify, con- & o "Engineers are responsible for conceptual \\
firm, apply, test and ensure." & designs and mathematical constructs \\
"Engineering technologists are respon- & whereas engineering technologists flesh \\
sible for operating, managing and super- & out these designs." \\
vising processes." & "Professional engineers are responsible for \\
& considered design and systematic/ method- \\
& ical problem solving." \\
\hline
\end{tabular}

Another key distinction is that DIT faculty see the role of the engineer as significantly bound up with design activities, and therefore the identity of the engineer aligns with becoming a designer, a creator of solutions. The role of technologist, even if it contains design elements, is not as fully invested in the design process. So, engineering technologists are involved in the more limited re-design of existing systems, whereas engineers are involved at a conceptual level (see Table 2).

Table 2. Design as an Identifying Role

\begin{tabular}{|l|l|}
\hline Design Role of Engineering Technologists & Design Role of Engineers \\
\hline ○"Engineering technology graduates will & "A professional engineer has the ability to \\
see "how we can make it better' rather than & $\begin{array}{l}\text { do research and design at the highest } \\
\text { level." }\end{array}$ \\
$\begin{array}{l}\text { designing new." } \\
\text { "Engineering technologists are involved in } \\
\text { design of sub-stations based on the modi- } \\
\text { fication of existing designs." }\end{array}$ & \begin{tabular}{c} 
deploy systems." \\
\hline
\end{tabular}
\end{tabular}

Faculty provided a range of views on engineering and engineering technology that included seeing them as overlapping disciplines characterized by different emphases on the one hand and different depth of activities on the other. Table 3 below illustrates this dichotomy of views. 
Table 3. Different Emphases and Different Depth

\begin{tabular}{|l|l|}
\hline Different Emphases & Different Depth \\
\hline o "Engineering and engineering technology & ○ "The level of application and depth of un- \\
are almost interchangeable terms." & derstanding are the key differences." \\
" "Engineering Technology is more hands- & "The difference is between mastering de- \\
on, practical focused, more applied, less & sign methods versus using technology to \\
theoretical, less mathematical, less analyti- & implement a solution." \\
cal." & ० "Engineering is at a superior level with re- \\
"Engineering technology students may & spect to analysis and understanding of \\
have fantastic applied knowledge but have & fundamental principles." \\
no analytic skills" &
\end{tabular}

Important from an identity perspective, faculty noted that engineering technology graduates generally see themselves as engineers and that the students themselves are not well positioned to differentiate between engineering and engineering technology. In putting themselves in the role of their graduating final year students, the educators commented as shown in Table 4 below.

Table 4. Identity and Confusion

\begin{tabular}{|c|c|}
\hline Identity & Confusion \\
\hline $\begin{array}{l}\text { "Engineering technologists would see } \\
\text { themselves as engineers." } \\
\text { o "Engineering Technology graduates } \\
\text { would characterize themselves as engi- } \\
\text { neers." } \\
\text { " "Recent technology graduates would de- } \\
\text { scribe themselves as engineers." }\end{array}$ & $\begin{array}{l}\text { O "Students don't see the difference be- } \\
\text { tween engineering and engineering tech- } \\
\text { nology." } \\
\text { o "Students could not yet describe them- } \\
\text { selves or their discipline." } \\
\text { "Students may not be able to characterize } \\
\text { the difference." }\end{array}$ \\
\hline
\end{tabular}

In summary, while understanding the curricular and academic differences in the education of the two groups, the faculty we interviewed acknowledged that (1) students about to graduate don't differentiate between engineering and engineering technology, (2) engineering technology graduates will see and identify themselves as engineers, and (3) there is a complete absence of identity as a technologist or engineering technologist. A question yet to be answered is to what extent the final year students' views of themselves have been shaped over the course of their studies at DIT by the views of their educators.

\section{Strand 2: Student Survey}

The findings for this portion of our work - the crux of our study - are gathered from students in their final year of study. We wanted information from students whose identities had been shaped (at least partially) by the educational culture they had engaged in for the preceding 3 or 4 years. Based on the results of the faculty interviews, we developed an on-line survey for final year students. This survey was tested and refined through separate 'talk aloud' sessions with four students from our target population: two from engineering technology and two from engineering programs. Of the population of 425 , a total of 153 students accessed the survey, for a response rate of $36 \%$. What we report below as significant meets the $95 \%$ threshold (meaning that there is less than a $5 \%$ chance that each difference we found was random). We also assessed the qualitative responses that students submitted to open-ended questions, looking for themes. 


\section{Quantitative Findings from Student Survey}

Regarding the survey, there were a number of questions where the two student groups responded in statistically different ways. Engineers ranked each of the following statements higher than technologists did:

(a) I want to use my knowledge to design and create new things.

(b) I can devise and generate new designs and solutions.

(c) My program has prepared me for a wide range of jobs after graduation.

(d) My program gave me detailed knowledge and understanding in my technical area (for example in mechanical engineering).

(e) I have focused significant efforts on developing competence in my profession.

(f) I have focused significant efforts on balancing my independence with my dependence on others.

(g) As a result of my program I can design new systems.

Engineering technology students ranked the following statement higher:

(h) I want to control and maintain equipment in an engineering environment.

The two groups responded in statistically similar ways to the items "my program has taught me how to apply my technical skills" ( $69 \%$ of students), "my program has taught me how to tackle problems creatively" ( $45 \%)$, and "my program has taught me how to develop/create successful new technologies" (14\%). However, the two groups responded differently to the statement that "my program has taught me how to solve problems I will face in the real world," with $66 \%$ of technology students ticking this box, but only $47 \%$ of engineers ranking this in their top two.

The survey included questions that were generated using Bloom's revised taxonomy (Lorin Anderson \& David Krathwohl, 2001; Benjamin Bloom \& David Krathwohl, 1956). In these questions, the majority of responses were similar for both groups: $42 \%$ of our population said that they had best mastered "to analyze things," $42 \%$ said they had best mastered "to understand things," 39\% said "to apply knowledge," $33 \%$ said "to evaluate things," $18 \%$ said "to remember things," and 14\% said "to create things." However, there was a difference on the item "to apply knowledge," for which $51 \%$ of technology students selected this as one of their top two responses. Just $31 \%$ of engineers did the same. Although this might appear to contradict the finding above that both groups responded similarly to the statement "my program has taught me how to apply my technical skills," what is important to realize is that engineering technology students selected "apply knowledge" as most important to them in selecting their top two choices. This is consistent with the qualitative findings described below regarding how both groups aligned around either 'design' (engineers) or 'apply' (technologists).

\section{Qualitative Findings from Student Survey}

The survey asked final year students to give a reason - in one sentence - as to why they chose to study their particular program. There were clear differences in the explanations provided by the two groups. For engineers, responses generally were along the lines of the student always knowing that they wanted to be an engineer, or that they always liked analytical subjects, or that they liked the possible careers and career paths that an engineering qualification would open up. For engineering technologists, the responses tended towards how the engineering technology degree would ensure 
the graduate would get a good job, or that the program was practical, or that the engineering technology program itself was a follow-on to an earlier program. In DIT this earlier program almost invariably is skills-based (such as electrician training). Some specific responses are provided in Table 5 below.

Table 5. Why did you choose to study this particular program?

\begin{tabular}{|c|c|}
\hline $\begin{array}{l}\text { Sample Responses of Engineering Technol- } \\
\text { ogists }\end{array}$ & Sample Responses of Engineers \\
\hline $\begin{array}{l}\text { O "I wanted to move up from being an elec- } \\
\text { trician and be able to work at a higher pro- } \\
\text { file" } \\
\text { "many job prospects afterwards" } \\
\text { o Job opportunities and an interest in ma- } \\
\text { chines" } \\
\text { "I chose this program because it was a } \\
\text { practical program that provided skills that } \\
\text { could be applied in the real world" }\end{array}$ & \begin{tabular}{|l} 
\\
"I felt it would give me the widest range \\
of career choices." \\
"I felt the degree would give me a lot of \\
options after graduation." \\
"Interest in maths, physics and all things \\
mechanical. I liked making stuff ..." \\
"Mechanical engineering keeps the world \\
ticking and I wanted to be part of that \\
background work" \\
"Buildings are great; the idea of applying \\
maths to create solutions for buildings is \\
exciting."
\end{tabular} \\
\hline
\end{tabular}

It must be emphasized that there were clear overlaps in the response types with, for example, engineers saying that "there are lots of jobs in engineering" and engineering technologists saying "I always want[ed] to design buildings". But, generally, engineers saw the study of engineering as a stepping stone to a career that was aligned with an inner sense (perhaps ill-defined) of the nature of engineering work - design that attracted them to study engineering. Technologists tended to have a more immediate horizon: the program was practical and hands-on and would lead to good job opportunities once they graduate.

We asked the final year students to describe what they wanted to do in their first job after graduating. Here, engineers generally responded along one of three themes: they wanted to work in design, or they wanted to gain experience by applying their knowledge, or they wanted to make money. One noteworthy response from an engineering student combines all three of these themes: "get as much money as possible and gain as much experience as possible in design[ing] different systems. Apply anything I've learned while in College." Table 6 below provides indicative responses by students to what they wanted to do in their first job.

Table 6. What do you really want to do in your first job after graduating?

\begin{tabular}{|c|c|}
\hline $\begin{array}{l}\text { Sample Responses of Engineering Technol- } \\
\text { ogists }\end{array}$ & Sample Responses of Engineers \\
\hline $\begin{array}{l}\text { O "Be an engineer" } \\
\text { "Be able to run equipment such as machin- } \\
\text { ery and be able to solve their problems" }\end{array}$ & $\begin{array}{l}\text { O "I would like to work in a design office } \\
\text { applying what I have done in my final year } \\
\text { project" }\end{array}$ \\
\hline $\begin{array}{l}\text { o "Plant maintainer with computer aided } \\
\text { skills" }\end{array}$ & $\begin{array}{l}\text { "Earn money and gain work experience" } \\
\text { "Get the most experience I can in technol- }\end{array}$ \\
\hline $\begin{array}{l}\text { o "Get a job in a programming environment } \\
\text { to control systems" }\end{array}$ & ogies that interest me" \\
\hline
\end{tabular}

The key action verb that differentiates the two groups is that engineers again and again brought the word 'design' into their responses: "I would love to work in a design 
engineering role", "develop independent design skills, learn to work creatively", "design the systems for buildings", "design to help people in any way I can", and "contribute to the skyline of a major city in the world, be involved in projects which reduce the carbon emission and energy use of the world using evidence based design, start on the road to becoming chartered, being referred to as Dr. would be nice and a healthy bank account would be an advantage."

While the engineering technologists did not exclude working in design or as part of a design team from their responses (e.g., "I want to get a graduate position in a design office"), the responses tended to be less career focused and more oriented to applying their skills (e.g., "I want to do something related to my skills", "utilize my skills and knowledge I acquired from my course"). Responses generally were openended but based on the knowledge and skills that they had acquired through their studies: "I am open to any type of work related to my program".

Lastly, we asked the final year students themselves what differences they perceive between people who leave college as "Engineers" and those who leave as "Engineering Technologists". The key finding was that significant numbers either gave no answer or said they did not know (37\% of engineers and 52\% of technologists). A further group said there was no difference (11\% and $10 \%)$. In total, two-thirds of technologists gave no answer, did not know or said there was no difference.

This seems to clearly align with statements by the faculty that technology students "may not be able to characterize the difference". We find further congruence with faculty views when we explore what were seen as the differences (see Table 7). The key differentiation was seen to focus on the issue of design. Engineers were more likely to be associated with design while technologists were seen to be more practical and involved with the implementation of designs. Engineers were also seen as better educated and having higher status.

Table 7. What differences do you perceive, if any, between people who leave college as "Engineers" and those who leave as "Engineering Technologists"?

\begin{tabular}{|c|c|c|}
\hline & Engineering Technology students said & Engineering students said \\
\hline $\begin{array}{l}\text { None/ } \\
\text { Don't } \\
\text { Know }\end{array}$ & $\begin{array}{l}\text { O"Didn't know there was a difference" } \\
\text { "There are no apparent differences, } \\
\text { they both have the same fundamental } \\
\text { background." }\end{array}$ & $\begin{array}{l}\text { O "None really. Generally most peo- } \\
\text { ple don't have a clue about the dif- } \\
\text { ferences between them. The only } \\
\text { people who point it out or are both- } \\
\text { ered by it are the 'engineers' and } \\
\text { the 'technologists' themselves." }\end{array}$ \\
\hline Recognition & $\begin{array}{l}\text { O "Engineering technologist doesn't } \\
\text { sound as good" } \\
\text { "Engineers may pursue a management } \\
\text { role" } \\
\text { "Engineers are more employable and } \\
\text { better educated" } \\
\text { "Engineers will get a job before engi- } \\
\text { neer technologists" } \\
\text { "Engineers are more respected" } \\
\text { "Engineers have more scope for pro- } \\
\text { motion and higher salaries." }\end{array}$ & $\begin{array}{l}\text { o "Engineers are probably more } \\
\text { highly thought of"; } \\
\text { o"Engineers have more opportunity } \\
\text {.... Engineering Technologist may } \\
\text { not be able to advance beyond a } \\
\text { certain level within their career } \\
\text { without further study." } \\
\text { o"You get more respect from lec- } \\
\text { tures, laboratory staff and future } \\
\text { employers." } \\
\text { "Less opportunities for technolo- } \\
\text { gists" } \\
\text { "Engineers have more responsibil- } \\
\text { ity" }\end{array}$ \\
\hline
\end{tabular}




\begin{tabular}{|c|c|c|}
\hline $\begin{array}{l}\text { Educational } \\
\text { Level }\end{array}$ & $\begin{array}{l}\text { "People who leave with a BE as op- } \\
\text { posed to a BEngTech have a more ad- } \\
\text { ministrative approach to engineering" } \\
\text { "Different lines of work, different lev- } \\
\text { els of degrees" } \\
\text { "Engineers have higher qualifications" } \\
\text { "Engineering Technologists are more } \\
\text { confident with practicality than the } \\
\text { theory" } \\
\text { "To me it's the fields chosen by the in- } \\
\text { dividual so there is no difference, both } \\
\text { have taken the course for their in- } \\
\text { tended career choice." }\end{array}$ & $\begin{array}{l}\text { "Engineers as a whole have } \\
\text { learned to learn"; } \\
\text { " "Engineers would be of a higher } \\
\text { educational standard"; } \\
\text { "Different level degree, almost } \\
\text { same knowledge"; } \\
\text { "Engineers know how and why } \\
\text { things happen while Engineering } \\
\text { Technologists are mostly shown } \\
\text { how things work" } \\
\text { "Engineers have achieved a } \\
\text { broader education in the field } \\
\text { whereas technologists have re- } \\
\text { ceived education in a more spe- } \\
\text { cific area of focus in Engineering." }\end{array}$ \\
\hline Function & $\begin{array}{l}\text { O "Engineers would be more inclined to } \\
\text { design and numerical analysis, where } \\
\text { as engineering technologists would } \\
\text { have a stronger sense of operation and } \\
\text { maintenance ...." } \\
\text { "Engineers can design things and ana- } \\
\text { lyze errors when building things. En- } \\
\text { gineering technologists focus more on } \\
\text { theories rather than technicalities." } \\
\text { "Engineers create design and develop } \\
\text { new technologies. Engineering tech- } \\
\text { nologists integrate existing technolo- } \\
\text { gies and systems." } \\
\text { "Engineers have more responsibilities } \\
\text { and are more involved in design } \\
\text { whereas engineering technologists op- } \\
\text { erate and carry out tasks." }\end{array}$ & $\begin{array}{l}\text { o"In my opinion, Engineers will } \\
\text { leave focusing their careers on the } \\
\text { design and evaluation of new tech- } \\
\text { nologies as [opposed] to engineer- } \\
\text { ing technologists who, in my opin- } \\
\text { ion, will focus more primarily as } \\
\text { technicians, maintaining systems, } \\
\text { carrying out tests, evaluations etc. } \\
\text { that the engineers have assigned } \\
\text { them." } \\
\text { "Engineering technologists will } \\
\text { have a more hands on job while en- } \\
\text { gineers will be more design or } \\
\text { management role" } \\
\text { "Engineers focus on using their } \\
\text { knowledge to design, improve and } \\
\text { innovate technology. Engineering } \\
\text { Technologists use their expertise } \\
\text { to operate and efficiently maintain } \\
\text { technology." }\end{array}$ \\
\hline
\end{tabular}

In a memorable comment on the difficulty of completing an engineering degree, one final year engineering student said of engineering technologists: "the latter leave college with around $€ 5,000$ less p/a and about 5\% more hair!!" In line with the earlier note that engineering technologists were more job-focused than career-focused, this group noted that the job, pay, and promotion prospects were better for engineers. Both groups, when comment was made, noted the higher standing or esteem that engineers would have. Finally, and again supporting the statistical results, both groups overwhelmingly used design activity as a key differentiator between the two.

Overall, what emerges from the survey is that both groups see themselves as having different roles and functions. Engineers are more likely to be seen as designers with a careers focus. Technologists have a narrower job focus, were seen as more practical and better prepared to tackle real world problems. While these differences can be identified in the responses to the full range of survey questions it is also the case that two-thirds of technology students were unable (or did not want) to distinguish themselves from engineers. This suggests a weak social identity as engineering technologists and an inability to distinguish themselves from engineers. 


\section{Strand 3: Prior DIT Surveys of First Year Students}

In considering the responses above (from faculty in Strand 1 and from final year students in Strand 2), the quantitative and qualitative differences between the two groups of students center on: (1) students' views on design as an identifying activity, (2) how they wish to use their education once they graduate, (3) their initial views on their future careers, and (4) their own development as engineers and people. To provide further insight, we contrast these responses from final year students with responses from an earlier DIT study of first year students that sought to examine why students chose to study engineering and why they chose to come to DIT for their studies.

Between 2003 and 2007, DIT conducted surveys of incoming engineering and engineering technology students in an effort to understand attraction and retention issues in engineering education. This work involved surveying students about why and how they chose an engineering-related field of study and why they selected DIT. The overall response rate was around $65 \%$ each year the study was conducted. These data have been reported previously (Eddie Conlon, 2006) but not analyzed statistically. We reviewed the findings of these prior studies. Then, we extended them by using statistics to compare the 2007 responses provided by engineering majors with those provided by technology majors. In 2007, a total of 525 students entered DIT's various engineering programs. Of these, 307 submitted responses from our target population of programs. We compared responses from the 114 engineering students with those provided by 193 engineering technology students. We wanted to better understand what motivated them to become engineers in the first place and see if there were different factors at play with the two groups.

The cohort of first year engineering and engineering technology students who commenced studying in DIT was asked to select, from a list of possible reasons, the two most important reasons they saw for choosing to study engineering. The survey results for 2007 show the percentages selected by incoming students:

- $41 \%$ chose "I was always interested in how things work" (46\% of engineers and $39 \%$ of technologists)

- $\quad 36 \%$ chose "I am interested in designing things" (28\% of engineers and $41 \%$ of technologists)

- $\quad 28 \%$ chose "Engineering is a good career" (28\% of engineers and $27 \%$ of technologists)

- $24 \%$ chose "I want to build things" (21\% of engineers and $26 \%$ of technologists)

This prioritization of response was consistent across the five years for which the survey was conducted. When we analyzed the 2007 response data for the two groups, we found that while $25 \%$ of engineering majors listed "I like maths and physics" as their first or second choice, just 14\% of technologists did likewise. Engineering majors were significantly more likely to have an engineer somewhere in the family ( $99 \%$ say they do as opposed to $94 \%$ of technology students). The technology students who did have an engineer in the family were likely to have just one (60\% as opposed to $51 \%$ of engineering majors). Significantly more of the engineers were influenced positively by an engineer ( $71 \%$ as opposed to $49 \%$ among technologists) or a mathematics teacher (58\% as opposed to $37 \%$ of technologists).

There were also significant differences in why the two groups chose to study at this institution. "DIT courses are more practical and applied" was important to $80 \%$ of engineers (i.e., among the student's top five choices) but just $62 \%$ of technologists. 
A significantly higher number of technology students selected "I like working with computers" as one of their most important reasons for selecting the career $(40 \%$ of technologists listed it, as opposed to $25 \%$ of engineers).

These survey responses raise two issues. Firstly, the engineers interviewed in 2007 were less likely than technologists to say they were interested in designing when they started their engineering studies, but those moving towards graduation in 2013 were more likely to see designing as a key distinguishing feature of their identity. Secondly, the engineers were more likely to say they came to DIT because the programs are more practical and applied (that at other institutions). Thsis needs to be understood in the context of the students having a choice to study at DIT or at a university that would have a more 'theoretical' orientation.

What can be noted is that the experience of studying at DIT seems to enhance the identity of engineers as designers but leaves them less prepared than technologists to solve real world engineering problems. It might be the case that their education as engineers in DIT is less practical than initially thought. This has clear implications for DIT in attracting and retaining students as it suggests a mismatch between the expectations of students and their actual experience in DIT.

Strand 4: Case Study - observations on how engineering students and engineering technology students approach a design problem

DIT has a design course titled "Engineering Practice and Design" (popularly known as RoboSumo), in which teams of students design and build a robot which then competes one-on-one against other student robots in a competition to locate and push the other robot from a round table. Teams are comprised of either second year electrical engineering technology students or first year electrical engineering students. Because the faculty interviews and student survey responses identified design as a differentiating factor between the two groups of students, we asked a colleague to describe his experience with both groups as they engage in the same design course. In the following case study, Dr. Ted Burke describes his observations of various approaches student teams take with regard to the RoboSumo design task. 
Case Study - How Students Approach a Design Problem - RoboSumo

"There are different design approaches that dominate within each cohort. In particular, the archetypal 'good' engineering technology team approach to design is to get 'stuck in' straight away and start building a robot. This sometimes appears rash - as though the team has completely bypassed the importan step of critically analyzing a proposed design before committing to it. Based on my observations however, this criticism is often not applicable. In fact, this early building behavior should be regarded more as a 'mocking up' exercise than as an attempt to produce the final design in a single hare-brained step. By building these flawed designs, teams learn a huge amount that will inform their final design. A mockup helps teams to build a shared understanding of design features and also to get a clearer sense of each other's strengths and weaknesses ("My team mate says he can cut and bend sheet metal, but can he really?". "My team mate swears she can get the program written by tomorrow - I suppose I'll wait and see if she can deliver.").

The fact that these teams are often perfectly happy to build the robot 'wrong' a couple of times before building it right reflects two significant factors: (1) the students' belief (which I share) that this approach (let's call it 'Build Early and Build Often' - BEBO) is a very effective way of learning; (2) The students' level of confidence in building physical things. Many of these engineering technology students have a lot of practical fabrication experience. Perhaps in the past they have found it rewarding to make physica things. As a result, many of these students probably assign a lower 'effort cost' to this approach than another student with less prior manufacturing experience would.

I would describe the archetypal weak engineering team approach as follows:

- Spend a lot of time thinking about the problem. This step typically involves a considerable amount of meditation, hand-wringing, soul-searching, and very occasionally critical analysis of proposed design features.

- Devise an ingenious, over-complicated solution, often with very fundamental design flaws (e.g., wheels attached directly to DC motors without any gearing).

- Underestimate the difficulty of building the proposed solution. By and large, our engineering RoboSumo teams of the last few years have seemed more confident with computers and less confident making physical things.

- Leave it until far too late to pull the whole thing together.

- Panic (optional).

The archetypal strong engineering team approach is actually something like the above, but with two critical differences: (a) for whatever reason, the thinking stage is much more fruitful. Terrible ideas are successfully weeded out without anybody needing to build anything. Good ideas are refined to make them more practical. Future problems are anticipated and possible solutions formulated. (b) A working prototype gets built much earlier, allowing wrinkles to be ironed out and the design (mechanical, electrical, software) to be tweaked as required. What's different here to the BEBO model is that more thinking happens before the first build, and there probably won't ever be a second build - just testing and refinement of the first prototype. Let's call this 'good engineering approach' Build Once After Thinking (BOAT).

BEBO versus BOAT

All in all, I see both approaches as very effective when done right. I suspect that good engineers will produce a good robot either way. Part of what draws some good engineer towards the BEBO approach is confidence in (or enjoyment of) building things, which I suppose is influenced to a large degree by prior experience. An engineer who is already in his or her comfort zone building things will assign a lower effort cost to mocking up design ideas to get a better feel for them. For such a person, BEBO is a reasonably painless strategy for shaping design ideas. By contrast, someone with less manufacturing experience may assign a higher effort cost to the same process since they have fewer existing skills to fall back on. Someone in this situation might be more naturally drawn to BOAT. For strong RoboSumo teams, I don't really mind which of the two approaches they use. However, for weaker teams, I'm inclined to nudge them towards BEBO, since they'll at least get a reality check early in the process about the complexity of the task (when their first prototype stinks)." 


\section{Discussion of Results}

Sense of Purpose: Arthur Chickering and Linda Reisser (1993) developed a framework for understanding the broad issues associated with identity development. These scholars theorized that college students develop their personal identities along seven primary "vectors", with development in each vector taking a unique direction and rate of speed. We had the students rank their own effort with regard to each of the following vectors:

1) Developing competence in my profession

2) Managing my feelings and emotions

3) Balancing my independence with my dependence on others

4) Developing mature relationships with others

5) Establishing my own personal identity

6) Developing a strong sense of purpose

7) Developing a sense of integrity in the way I behave

More often than technologists, the engineering students in our survey reported a focus on developing professional competence and balancing independence with dependence on others. On the other hand, technologists indicated greater focus on developing a "strong sense of purpose". These responses suggest that the engineers are more careeroriented and that technologists have focused on more general (less profession specific) aspects of their identities.

Aligning Identity with College Values: First year surveys demonstrated that both sets of students had a very practical orientation as they entered DIT. This practical orientation is underlined by consistent responses across all programs as to why students chose to study at DIT. In all years the most popular response was that "DIT has a good reputation for engineering," followed by "DIT courses are more practical and applied". These findings support the outcomes of research by the IEEE (2003) in which student respondents indicated that their primary reason for doing engineering was that they "wanted to invent, build or design things".

However, the survey and the case study point to a divergence in how both groups of students see themselves being prepared for the "real world" they will shortly face. Engineering technology students were significantly more comfortable with the statement that "my program has taught me how to solve problems in the real world." The case study also highlighted that engineering students today may not be as confident making physical things (e.g., robots in the case study) and this also can generate a self-perception of not being prepared for the real world, especially if the student came to DIT expecting it to be practical and hands-on. One could also speculate that the difference in confidence in preparedness for the real world is related, in part, to the open-endedness of design: technologists see themselves as doing more deterministic work (i.e., applying concrete principles to specific situations in a prescribed fashion), whereas engineers see themselves confronted with problems which don't yet have a solution and they will be expected to find one by conjuring up a design (which might appear to them as a more daunting task).

There is a difficulty for DIT in aligning the expectations of students with the requirements for professional engineering. This difficulty is made more difficult in that the Institute has to attract and retain students of engineering and engineering technology. The latter may require a greater emphasis on the practical nature of DIT pro- 
grams. But this may lead to the wrong message being conveyed to engineering students (as per Strange \& Banning, 2001) who may not be prepared for a program of study that may be a good deal more analytical and theoretical than they expect.

Intrinsic Motivation and Role: Our surveys of incoming freshmen students consistently highlighted that students chose their program because they were "always interested in how things work", followed by "I am interested in designing things". It is evident that DIT students were primarily attracted to engineering by intrinsic features of engineering and their desire to understand and design. This motivation persisted through their studies and exhibited strongly in their responses to the final year student survey, in which they strongly identified (both qualitatively and quantitatively), $d e$ sign as a key competence of an engineer, a key differentiator between engineer and engineering technologist, and a key career activity for the engineer.

Although engineers consistently used design as a generic description of what they will do as professional engineers, their responses indicated they may not have a strongly developed understanding of the role of a design engineer. Nevertheless, design was used as a general descriptor of what the new graduate expected do upon entering the workforce. There was a clear disconnection between the students' identity as designers and their perception of their capacity to solve real world problems.

Absence of Identity: While faculty members, engineering students and engineering technology students could all distinguish the role and function of engineers and technologists, there was weakly shared identity that was specific to students in engineering technology. They saw themselves as engineers but with different roles (see Ronald Land 2005). This finding is not surprising, given that up to half of these DIT students will eventually progress to an engineering program. In a sense, being an engineering technologist is not a goal for many of these students. But this absence of a strong identity can create difficulties in attracting and retaining students, because prospective students have little against which they can match their interests and aspirations. In the US context Land (2012) has made the point that "The lack of distinction (between engineers and technologists) has led to a number of persistent problems. Among them has been an inability of engineering technology programs to define themselves to potential students and their parents" (33).

Although faculty members can identity the role and function of technologists, they have not been able to convey a strong sense to students of the difference between them and engineering students. Indeed the faculty perceives difficulties the students have in understanding their role. This may raise an issue regarding the professional education of these students and the extent to which they are getting a broad education that will help them understand their specific role.

\section{Conclusion}

In this chapter we have explored the identities of engineering and engineering technology students in a large Institute of Technology in Ireland. A key finding is that faculty and students do differentiate between the two groups; the two are seen to have different roles and functions. The concept of engineers as designers emerged as a key characteristic distinguishing engineering from technology students. Both groups see 
engineers as career-oriented designers and both groups see technologists as more practical implementers. Technologists have a greater job orientation and a greater drive to apply knowledge in order to solve real world problems.

Despite these findings, the identity of 'technologists' is weak. According to faculty members, the engineering technology students see themselves as engineers. Our survey revealed that many of these technology students can't, or perhaps won't, distinguish themselves from engineers; they may not be designers but that does not mean they are not engineers. While design is a key issue, this does not seem to prevent technologists from seeing themselves as 'engineers'. That choice seems related to how they understand and define the activity of 'engineering' itself. For them engineering is comprised of many different roles.

The commonly shared sense of identity is stronger among the engineering students. DIT students' image of what an engineer does seems to be stronger than of what a technologist does. Overall, engineering students seem clearer about what they think the profession holds than technologists are. They probably developed a stronger professional understanding in college (after all, they have been here one year longer than the technologists and thus have had more time to construct a shared conception and/or adopt one handed to them by teachers and professional advisors). However, they also brought a stronger understanding with them when they arrived. These engineering majors had greater exposure to the profession than the technology students. They were more likely to have an engineer in the family and to have had positive experiences with an engineer in the past. As such, the engineers probably entered with a stronger sense of occupational identity than the technologists did.

As indicated earlier, we used Ireland's accreditation standards as a guide in drafting some survey questions - to see if differences implied in the standards were clear to DIT students. These standards suggest technology is more applied and engineering is more theoretical and design-oriented. The students describe some key factors that professional bodies and their teachers see as distinguishing 'technologists' from 'engineers'. Although they picked up on some differences, they did not distinguish more subtle delineations. Responses to "I can compare different technical solutions and make recommendations" and "I can use a range of engineering tools and methodologies" did not receive significantly different response rates, for instance. (Irish accrediting standards tag the first to technologist and the second to engineers.) In the net, however, we found evidence that occupational enculturation is part of the experience in DIT's schools of engineering.

Our research suggests some challenges for DIT in addressing issues of professional identity in its engineering programs. Firstly, many engineering students come to DIT expecting a practical education. The perception that "DIT courses are more practical and applied" was significantly more important to engineers than to technologists. These engineering students have often chosen DIT over a university because of the appeal of its hands-on pedagogical approach. At the end of their educations, their identity as designers has been enhanced but they feel less prepared than technologists to solve real world engineering problems. This has implications for DIT in attracting and retaining students, because it suggests there could be a mismatch between the expectations of students who want a practical education and the more theoretical and analytical knowledge they ultimately feel they have received.

Society and school play important roles in shaping the professional identity of engineering students, but the same cannot be said for engineering technologists. It is not 
nearly as clear to students what technologists do and how technologists' work differs from what engineers do.

Faculty members believe that students have a weak identity as technologists and do not distinguish themselves from engineers. Although faculty members articulate distinctions, a distinct professional identity, for technologists, has not been generated. This could be because the role is seen as somehow secondary to professional engineers. This could be unique to DIT, because the ladder system here allows students to easily move from technology into engineering. But it is somewhat worrisome that no clear identity is being offered to prospective technology students against which they could match their interests and aspirations.

The above presents a challenge for this multi-level institution as it seeks to grapple with the complexities of engineering identity and seeks to convey to prospective students the similarities and distinctions in the roles of engineers and technologists. The shared sense of role and professional identity of the engineer seem to be understood and communicated to students but the role of technologist, while understood, is not communicated as part of a wider professional identity.

\section{Acknowledgements}

The authors, and in particular Mike Murphy, would like to thank Steen Hyldgaard Christensen for all of his support and encouragement to complete the work for this chapter.

\section{References}

Anderson, Kevin John Boyett, et al (2010). Understanding engineering work and identity: a crosscase analysis of engineers within six firms, Engineering Studies, 2 (3), 153-174.

Anderson, Lorin. W. \& Krathwohl, David, et al (Eds.) (2001). A Taxonomy for Learning, Teaching, and Assessing: A Revision of Bloom's Taxonomy of Educational Objectives. Allyn \& Bacon. Boston, MA (Pearson Education Group).

Bloom, Benjamin S. \& Krathwohl, David (1956). Taxonomy of Educational Objectives: The Classification of Educational Goals, by a committee of college and university examiners. Handbook I: Cognitive Domain. NY, NY: Longmans, Green

Beder, Sharon (1988). The New Engineer, Macmillan, Sydney.

Chickering, Arthur W., \& Reisser, Linda (1993). Education and identity, (2nd ed.). San Francisco: Jossey-Bass.

Conlon, Eddie (2006). Recruiting first year engineering students, SEFI Annual Conference, Uppsala, Sweden, June 2006

Downey, Gary, Lucena, Juan, Mitcham Carl (2007). Engineering Ethics and Identity: Emerging Initiatives in Comparative Perspective. Science \& Engineering Ethics, Springer, Vol 13, No. 4.

Hogg, Michael A. and Terry, Deborah (2000). Social Identity and Self- Categorisation Processes in Organisational Contexts, Academy of Management Review, 25 (1), 121-40.

Iacovos, Nicolaou \& Conlon, Eddie (2013). The Integration of sustainable development competencies in Irish Engineering Education: Findings of a curriculum content investigation of four engineering programmes, Paper to Engineering Education for Sustainable Development Conference, Cambridge, September 2013.

IEEE Spectrum and IEEE-USA, Professional Image Study, December 2003

Jamison, Andrew (2013). The Making of Green Engineers, Morgan and Claypool.

Land, Ronald E. (2012). Engineering Technologists are Engineers, Journal of Engineering Technology, Spring 2012

Leidner, Robin (2006). Identity and Work. In Social Theory at Work, edited by M. Korczynski et al. Oxford University Press.

Mann, Llewellyn et al., (2009) Influences on the Development of Students' Professional Identity as an Engineer, Proceedings of the Research in Engineering Education Symposium 2009, Palm Cove, QLD

Meiksins, Peter \& Smith, Chris (1996). Engineering Labour. Verso: London and New York. 
Meyers, Kerry L., Ohland, Matthew W., Pawley, Alice L. \& Christopheronson, Cody D (2010). The Importance of Formative Experiences for Student Identity, International Journal of Engineering Education, 26 (6), 1550-1560.

Mulcahy Report (1967). Steering Committee on Technical Education, Report to the Minister for Education. Dublin.

Pawley Alice, L. (2009). Universalised Narratives: Patterns in How Faculty Members define "Engineering", Journal of Engineering Education, 98 (2).

Pierrakos, Olga, Thi Kay Beam, Constantz Jamie, Anderson Robin (2010). On the Development of a Professional Identity: Engineering Persisters Vs Engineering Switchers, Draft Manuscript Submitted for the "Engineering Learning" Workshop at ICLS 2010, June 28, Chicago, IL.

Sheppard, Sheri D., Macatangay, Kelly, Colby, Anne, Sullivan, William M. (2009). "Educating Engineers - Designing for the Future of the Field" Jossey Bass.

Smith Chris (1987). Technical workers, class, labour and trade unionism. Macmillan: London. Stets, Jan E. and Burke, Peter J. (2000). Identity Theory and Social Identity Theory, Social Psychology Quarterly, 63 (3).

Strange, Carney C. \& Banning, James H. (2001). Educating by design: Creating campus learning environments that work. San Francisco: Jossey-Bass.

Stevens, Reed, O’ Connor, Kevin, Garrison, Lari, Jocuns, Andrew, Amos, Daniel A. (2008). Becoming an Engineer, Toward a Three Dimensional View of Engineering Learning, Journal of Engineering Education, 97 (3).

Thompson, Paul \& Mc Hugh, David (2002). Work Organisations. $3^{\text {rd }}$ Ed., Palgrave

Watson, Tony (1997). Sociology, Work and Industry. $3^{\text {rd }}$ Ed., Routledge.

Wisnioski, Matthew H. (2012). Engineers for Change, MIT Press. 